\title{
Gastroenterology Practice Consolidation in the United States: Causes, Caveats, Consequences, and Calls to Action
}

\author{
Claire E. O'Hanlon ${ }^{1} \cdot$ Arpan Patel $^{2}$
}

Accepted: 20 January 2022 / Published online: 23 February 2022

This is a U.S. government work and not under copyright protection in the U.S.; foreign copyright protection may apply 2022

The relentless consolidation of the US health care industry [1] has spread to the practice of gastroenterology, which, despite previous resistance [2] and persistent fragmentation [3], is belatedly being consolidated. In this issue of Digestive Diseases and Sciences, the authors of "Gastroenterology Practice Consolidation Between 2012 and 2020" [4] report that practice consolidation in gastroenterology has increased precipitously in recent years. Despite a $9 \%$ increase in the number of gastroenterology physicians in practice from 2012 to 2020 , the total number of practices has decreased by $14 \%$. Importantly, these trends, observable in every region of the country, are expected to continue [5]. For gastroenterology practices, organizational leaders, and policymakers, understanding the causes and effects of consolidation are critical.

Though this study was not designed to understand why gastroenterology practice consolidation is occurring, the authors commented on a few perceived benefits to physicians that may drive it. The most obvious benefit is the economies of scale-as reporting and reimbursement complexity has increased, it makes more sense to spread administrative costs over a larger number of physicians. Other benefits might be considered physician "lifestyle" benefits, such as making

Disclaimer: The views expressed are those of the authors and do not necessarily reflect the position or policy of the Department of Veterans Affairs or the United States Government.

Claire E. O'Hanlon

Claire.O'Hanlon@va.gov

Arpan Patel

ArpanPatel@mednet.ucla.edu

1 Center for the Study of Healthcare Innovation, Implementation and Policy, Veterans Affairs Greater Los Angeles Healthcare System, 11301 Wilshire Blvd (151), Los Angeles, CA 90073, USA

2 Center for the Study of Healthcare Innovation, Implementation and Policy, Veterans Affairs Greater Los Angeles Healthcare System, UCLA David Geffen School of Medicine, Division of Digestive Diseases, 11301 Wilshire Blvd (151), Los Angeles, CA 90073, USA it easier to take time off by sharing caseloads and on-call duties. Pressures created by reimbursement cuts and valuebased payment models [6] may also drive decisions toward consolidation; such pressures have likely been exacerbated during the COVID-19 pandemic [7]. Increasing practice size improves physicians' bargaining position with payers when negotiating reimbursement rates for services, enabling them to charge higher prices [5].

Though the benefits to physicians are clear, the benefits of consolidation to patients and society are less so. A large body of research has demonstrated that consolidation between close competitors increases prices without improvements in quality or efficiency, with inferior patient outcomes where there is a lack of competition [1]. Furthermore, health care consolidation can negatively impact access to care for vulnerable individuals when physicians become bound by the policies of their physician group. In contrast with other industrialized nations with nationalized health care systems and social benefit programs, the social safety net in the USA consists of a patchwork of programs (e.g., Medicaid), laws (e.g., EMTALA [Emergency Medical Treatment and Labor Act]), and facilities (e.g., Federally Qualified Health Centers [FQHCs]) to try to maintain access to care for lowincome and uninsured people. Specialty, non-emergency care-much of the care provided by gastroenterologistsis an area in which patient care navigators at FQHCs may rely on personal relationships with physicians who provide occasional free or discounted care, since it is otherwise difficult to obtain. When physicians cede ownership or governance of their practice, these relationships can be disrupted. Indeed, qualitative analysis of the impacts of consolidation performed by one of the authors of this editorial (C.E.O.), identified screening colonoscopies, a service rendered by gastroenterologists, as a service that became more difficult to obtain for FQHC patients due to health care consolidation, since physicians whose practices were acquired by a large health care system were prohibited from using its equipment and staff to serve patients who were unable to pay [8]. 
Ways to mitigate the negative impacts of consolidation for patients and society are urgently needed. Although the policy environment with respect to consolidation is evolving [9], state and federal policymakers may need to address consolidation's negative consequences, perhaps through legislation to address rising health care costs resulting from consolidation. Professional societies such as the American Gastroenterological Association, the American College of Gastroenterology, the American Society for Gastrointestinal Endoscopy, and the American Association for the Study of Liver Diseases are in the position to lobby for legislative change to address these issues on behalf of their membership.

Since the benefits of consolidation to physicians are significant, and practice consolidation, unlike mergers of hospitals or insurers, rarely triggers the monetary thresholds that would subject them to regulatory scrutiny [10], the trend of gastroenterology practice consolidation is unlikely to slow down any time soon. In the absence of policy change, practicing gastroenterologists can actively participate in their practice governance. By taking steps to maintain their autonomy, they can continue to care for the most vulnerable patients at their own discretion.

\section{References}

1. Gaynor M. Examining the Impact of Health Care Consolidation. Statement before the Committee on Energy and Commerce
Oversight and Investigations Subcommittee. In: U.S. House of Representatives, 2018.

2. Casalino LP, Pham H, Bazzoli G. Growth Of Single-Specialty Medical Groups. Health Affairs. 2004;23:82-90.

3. Gilreath M, Morris S, Brill JV. Physician Practice Management and Private Equity: Market Forces Drive Change. Clin Gastroenterol Hepatol. 2019; 17:1924-1928.e1922.

4. Griffin ZD, Hogan J, Pollock JR, Moore ML, Mehta D. Gastroenterology Practice Consolidation Between 2012-2020. Dig Dis Sci. (Epub ahead of print). https://doi.org/10.1007/ s10620-022-07417-8.

5. Gilreath M, Patel NC, Suh J, Brill JV. Gastroenterology Physician Practice Management and Private Equity: Thriving in Uncertain Times. Clin Gastroenterol Hepatol. 2021;19:1084-1087.

6. Dorn SD. Are Value-Based Payments Bumps in the Road or the Road to Nowhere? Gastroenterology. 2018;155:587-591.

7. Forbes N, Smith ZL, Spitzer RL et al. Changes in Gastroenterology and Endoscopy Practices in Response to the Coronavirus Disease 2019 Pandemic: Results From a North American Survey. Gastroenterology. 2020;159:772-774.e713.

8. O'Hanlon CE. Impacts of Health Care Industry Consolidation in Pittsburgh, Pennsylvania: A Qualitative Study. INQUIRY: J. Health Care Organ. Prov., Financ. 2020;57:0046958020976246.

9. Statement of FTC Chair Lina M. Khan and Antitrust Division Acting Assistant Attorney General Richard A. Powers on Competition Executive Order's Call to Consider Revisions to Merger Guidelines [press release]. July 92021.

10. Abelson R. Small, Piecemeal Mergers in Health Care Fly Under Regulators' Radars. The New York Times. April 8, 2016, 2016.

Publisher's Note Springer Nature remains neutral with regard to jurisdictional claims in published maps and institutional affiliations. 